\title{
PLACENTAL TRANSFUSION AND FLUID METABOLISM ON THE FIRST DAY OF LIFE
}

\author{
BY \\ RUTH L. CORT and HANA PŔIBYLOVÁ \\ From the Institute for the Care of Mother and Child, Prague, Czechoslovakia
}

(RECEIVED FOR PUBLICATION JANUARY 27, 1964)

So-called placental transfusion has received increasing attention in recent years. The subject has been reviewed (Lancet, 1962) from the point of view of the theoretical and practical consequences of deliberately allowing a relatively large transfer of blood to the infant immediately after birth, rather than leaving the size of 'transfusion' to chance and purely obstetrical considerations.

In theory, placental transfusion should have a number of important physiological effects, particularly in the period of rapid postnatal adjustment to extrauterine life. A large, uninterrupted 'venous return' through the umbilical vein during the first breaths might influence the success of the establishment of pulmonary ventilation. A preliminary report of some of our findings in this regard has already appeared (Cort, Přibylová and Znamenáček, 1962).

One can further postulate that the acquisition or lack of an amount of blood estimated at some $20^{\circ}{ }_{o}^{\prime}$ of the total blood volume in newborn infants should be evident in metabolic and fluid adjustments in the neonatal period, probably through filling of the vascular bed and distribution of blood flow.

This report is concerned with renal function and some extrarenal parameters of body fluid metabolism in infants given a maximal or minimal placental transfusion.

\section{Methods}

Newborn infants born after normal pregnancies and labours were studied during the first day of life, at 48 , and 72 hours after birth. At birth, the umbilical cord was clamped either before the first visible breath or after being left undisturbed for three minutes. Note was made of the baby's general vigour and condition, the time of the first breath and cry, and of clamping the cord. Residual placental blood obtainable from the cut cord was measured within three minutes of severing the cord.

Provision for urine collection (Cort, 1961) was made within 15 minutes of birth, and urine was checked at three-hourly intervals up to 24 hours. Urinary urea, $\mathrm{Na}$,
$\mathrm{K}$, and $\mathrm{Cl}$ were determined as previously described (Cort, 1962) in individual urine specimens. Blood for determination of haematocrit, red cell count, and urea, was taken from the cord at birth and by heel prick at 1, 3, 6, 12, 24, 48, and 72 hours. All methods used were ultramicro and are described elsewhere (Cort, 1962).

The crying vital capacity (Sutherland and Ratcliff, 1961) was measured at $1,3,12,24,48$, and 72 hours after birth. Rectal and skin temperatures were measured at similar time intervals, as was systolic blood pressure (Ashworth, Neligan and Rogers, 1959). Leg volume was determined by water displacement at $1,2,3,6,9,12,18$, and 24 hours by a modification of the method described by Sutherland, Oppe, Lucey and Smith (1959).

Infants received nothing by mouth for the first 24 hours and were put to the breast shortly after 24 hours. Milk intake from the breast (by weighing) was noted in infants of primiparous mothers.

Since freezing point determinations could not be carried out on the diluted urine specimens, 'milliosmolar' urinary concentration was calculated approximately as $2(\mathrm{Na}-\mathrm{K})$ - urea $/ \mathrm{l}$.

In all, 30 infants were studied, though all determinations were not complete in all cases.

\section{Results}

Estimated Placental Transfusion. Considerable variation was found in the amount of blood obtainable spontaneously from the placental end of the cut cord, although the amount in the group following early clamping of the cord was larger (Table 1 ).

TABLE 1

\begin{tabular}{|c|c|c|c|}
\hline & & Average (ml.) & Range (ml.) \\
\hline $\begin{array}{l}\text { Early clamping } \\
\text { Late clamping . . }\end{array}$ & $\begin{array}{l}\cdots \\
\cdots\end{array}$ & $\begin{array}{l}98 \\
26\end{array}$ & $\begin{array}{c}75-120 \\
0-75\end{array}$ \\
\hline
\end{tabular}

The wide range of residual placental blood is in agreement with data in the literature (Taylor, Egan, Birchard, Bright and Wolfson, 1961). Even if given the opportunity, some apparently normally robust 


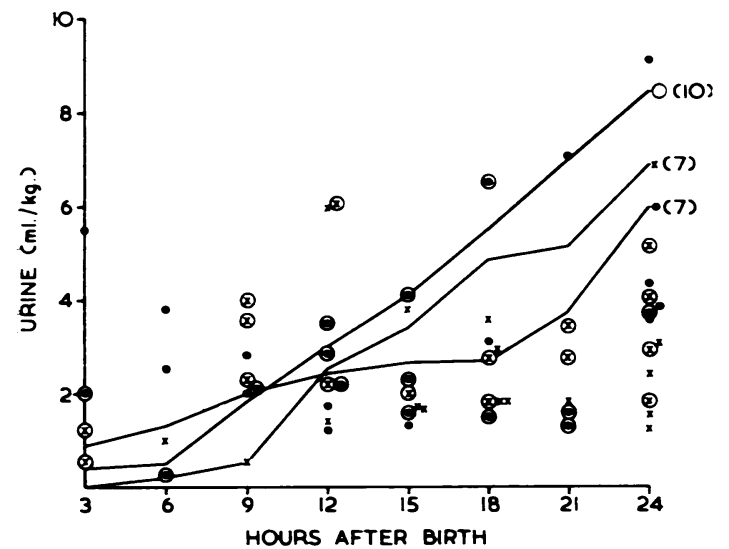

Fig. 1.-Amounts of urine passed by normal newborn infants during the first day of life. $X$, large placental transfusion, placental transfusion, $O$, babies weighing $3,700 \mathrm{~g}$. or more at birth The average cumulative amount of urine is drawn for each group.

newborn infants do not drain the placenta of blood. There was no obvious relation to the presence or absence of uterine contractions, though data were insufficient to prove this.

Urinary Output and Estimated Urinary Osmolarity. The group of 24 infants with satisfactory urine collections urinated on the average two to three times during the first day (out of seven three-hourly checks), but one infant passed no urine at all. The average

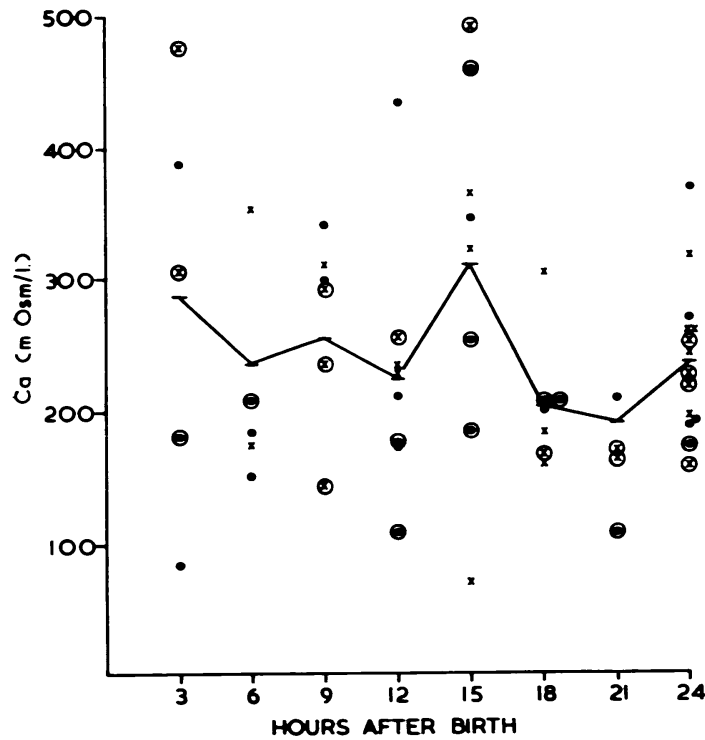

FIG. 2.-Estimated urinary milliosmols/1. of urine passed by infants as shown in Fig. 1. A verage for all 24 infants is drawn. Symbols as in Fig. 1. 'milliosmols' $=2(\mathrm{Na}+\mathrm{K})+$ urea. amount of urine in the first 24 hours was $26 \cdot 3 \mathrm{ml}$., with a range of 5.4 to $48 \cdot 0 \mathrm{ml}$.

The rate of urine flow could not be calculated accurately, since the interval between urine formation and micturition could be estimated in only a few cases. Effort was made to empty the bladder at three-hourly intervals (by crying and gentle suprapubic pressure), but we did not catheterize. There was wide variation in the apparent rate of urine flow in these fasting and thirsting infants, from $5 \cdot 4$ $\mathrm{ml}$. in $\mathbf{2 4}$ hours to some nine times this amount.

Fig. 1 is a scattergram of the times and amounts of urine passed by three groups of infants: 'small' babies (less than $3,700 \mathrm{~g}$. birth weight) with either large or small transfusion and 'large' babies of birth weight $3,700 \mathrm{~g}$. or more, who were placed in a separate group for reasons discussed below. The group of 10 'large' infants included 5 with early clamping of the cord and 5 with late.

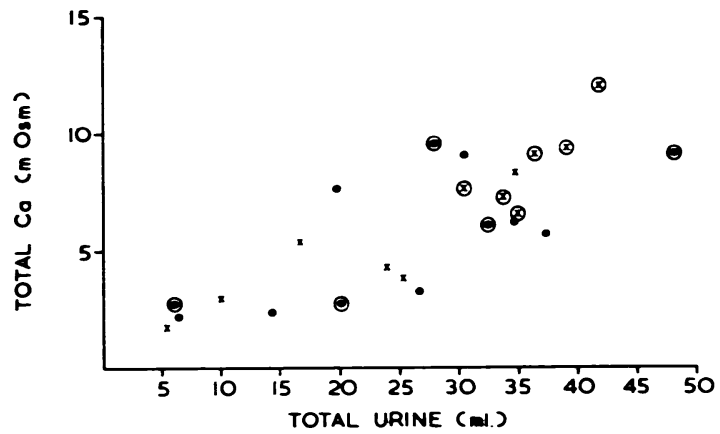

FK. 3.-Total urinary output (ml.) versus total estimated milliosmols excreted in urine. Symbols as in Fig. 1.

None of the differences in urine flow between groups is significant in the statistical sense. Two points may be noted, however: infants with a maximal placental transfusion apparently tended to pass urine at a steady increased rate from 9 hours, while those with a minimal placental transfusion showed a sustained increase in urine flow only after 21 hours. In fact, however, in both groups about the same proportion of infants urinated at similar time intervals after birth. The large infants showed a higher rate of urine flow from 6 hours of age.

Fig 2 serves to emphasize the finding that, during the first day of life, calculated urinary osmolarity showed no striking relation to progressive dehydration or, comparing Figs. 1 and 2, to the average rate of urine flow.

Fig. 3 shows the relation between total urine output and the total milliosmolar excretion. In general, above a total urine volume of $15-20 \mathrm{ml}$. during the 
TABLE 2

URINARY OUTPUT OF 24 NORMAL NEWBORN INFANTS IN THE FIRST DAY OF LIFE

\begin{tabular}{|c|c|c|c|c|c|c|c|}
\hline & Cord & Number & $\begin{array}{l}\text { Birth } \\
\text { Weight } \\
\text { (g.) }\end{array}$ & $\underset{\text { (ml. kg.) }}{\text { Urine }}$ & $\frac{\mathrm{Na}}{(\mathrm{mEq} \mathrm{kg})}$ & $\underset{(\mathrm{mEq}}{\mathrm{K}} \mathrm{kg})$ & $\begin{array}{c}\text { Urea } \\
\text { Production } \\
\text { (mg /kg) }\end{array}$ \\
\hline \multirow{2}{*}{$\begin{array}{l}\text { Small babies } \\
<3.700 \mathrm{~g} .\end{array}$} & $\begin{array}{l}\text { Early clamped } \\
\text { Late clamped }\end{array}$ & 7 & $\begin{array}{l}3.244=136 \\
3.197=238\end{array}$ & $\begin{array}{l}7 \cdot 5=3 \cdot 8 \\
6 \cdot 7=3 \cdot 4\end{array}$ & $\begin{array}{l}0.19=0.06 \\
0.22=0.13+\end{array}$ & $\begin{array}{l}0.25=0.15 \\
0.19=0.08\end{array}$ & $\begin{array}{l}81=42 * \\
49=17 *\end{array}$ \\
\hline & Total & 14 & & $7 \cdot 0=3 \cdot 1$ & $0 \cdot 21=0 \cdot 10^{+}$ & $0 \cdot 22=0.12$ & \\
\hline \multirow{3}{*}{$\begin{array}{l}\text { Large babies } \\
>3.700 \mathrm{~g} .\end{array}$} & $\begin{array}{l}\text { Early clamped } \\
\text { Late clamped }\end{array}$ & $\begin{array}{l}5 \\
5\end{array}$ & $\begin{aligned} 4.068 & =242 \\
3.784 & =70\end{aligned}$ & $\begin{array}{l}7 \cdot 2=4 \cdot 1 \\
9 \cdot 6=2 \cdot 0\end{array}$ & $\begin{array}{l}0.25=0.17 \\
0.37=0.08+\end{array}$ & $\begin{array}{l}0 \cdot 29=0 \cdot 10 \\
0 \cdot 29=0 \cdot 20\end{array}$ & $\begin{array}{l}57=33 \\
60=46\end{array}$ \\
\hline & Total & 10 & & $8 \cdot 4=3 \cdot 4$ & $0 \cdot 32=0 \cdot 13_{+}^{+}$ & $0.29=0.14$ & \\
\hline & Cord abnormality & $4 \S$ & $3.672=235$ & $8 \cdot 8=2 \cdot 3$ & $0 \cdot 36=0 \cdot 10$ & $0 \cdot 29=0.10$ & $65=38$ \\
\hline
\end{tabular}

$* t=6 \cdot 26 . \mathrm{p}<\cdot 01 .+\mathrm{t}=2 \cdot 65, \mathrm{p}>\cdot 02<\cdot 05 .+-\mathrm{t}=2 \cdot 32 . \mathrm{p}>\cdot 02<\cdot 05$. \$—includes $2 \cdot$ large'. 2 'small' babies. 3 early, 1 late clamped. Figures in italics indicate significant differences bet ween groups.

first day of life, total osmolar output was directly related to the total amount of urine passed.

Table 2 summarizes the urinary outputs of various groups of infants. The 24 infants with satisfactory urine collections are divided into groups according to (a) whether they were allowed to receive maximal or minimal placental transfusions and (b) by birth weight. In addition, 4 infants with demonstrable abnormalities of the cord circulation at birth were placed in a separate group as well as being included in one of the other groups. The latter included 2 infants in whom a needle was introduced into the umbilical vein for removal of blood samples: the total blood loss was small (10-15 ml.), but the procedure almost certainly lowered the pressure in the umbilical vein. One infant had a true knot in the cord and in the fourth the cord was tightly wound twice about the neck. Neither of the last two, however, had any signs of intrapartum foetal distress.

The differences between groups, which are significant, are given in italics. The 'large' infants

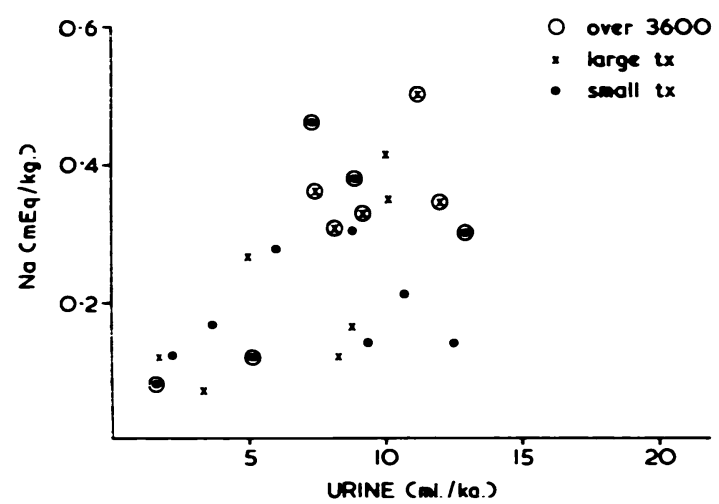

FiG. 4.- - C rinary output (ml. kg.) versus Na excretion (mEq kg.) during the first day of life. Symbols as in Fig. 1. excreted more $\mathrm{Na} / \mathrm{kg}$. than the smaller, and tended to pass larger amounts of urine, although variation was wide.

Urine volumes and $\mathrm{Na}$ output are plotted in Fig. 4. Two tendencies are apparent: first, $\mathrm{Na}$ excretion tends to increase in many instances with increasing urine flow (as total milliosmolar excretion), and second, the smaller babies tend to fall below the level of larger babies. There are 3 exceptions among the smaller infants who excreted $0 \cdot 3 \mathrm{mEq} \mathrm{Na} / \mathbf{k g}$. or more. Of these 3,1 had a knot in the cord, 1 was born with heavy meconium staining and probably acute anoxia, although lively, and the third unexpectedly had a temperature of $39^{\circ} \mathrm{C}$. on the third day of life, with no other overt signs of infection. Of the 2 large baby exceptions, with less than $0.15 \mathrm{mEq} /$ $\mathrm{kg}$. $\mathrm{Na}$ in the urine, one was clinically quite normal, while the other had a loud systolic murmur with no signs of cardiac failure (normal respiration and blood pressure).

Other correlates to $\mathrm{Na}$ excretion will be discussed in the section on shifts in body fluids.

The differences in urea production between smaller babies with early or late clamping of the umbilical cord were significant. Fig. 5, which illustrates the relation between urea appearing in the urine and the average blood urea during the first day of life, indicates that, in almost all cases, failure of renal urea excretion cannot be invoked to explain these differences. By far the most important determinant of total urea excretion was the amount of urea 'appearing' or 'produced', as calculated from the change in blood urea levels and the total urinary urea output.

It was possible to study the relation between urea production and other physiological parameters measured during the first day of life. Fig. 6 shows a highly significant inverse relation between the crying vital capacity (in average $\mathrm{ml} . / \mathrm{kg}$.) and urea production in $\mathrm{mg} . / \mathrm{kg}$. The relation, though clear, is not 


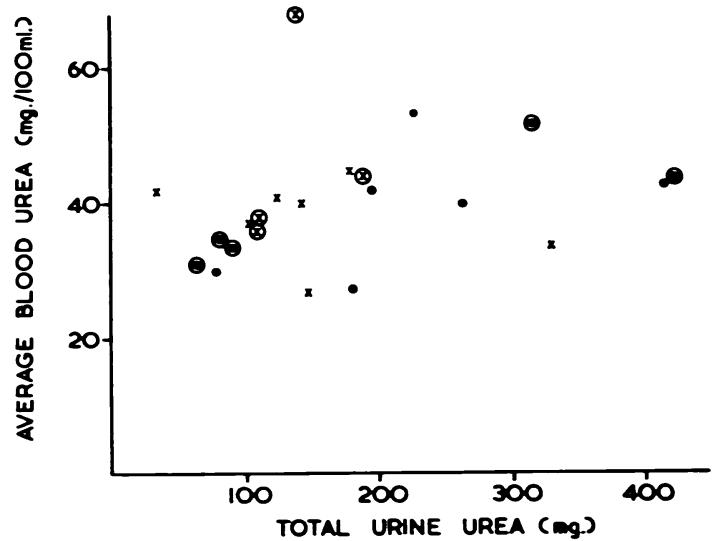

Fkg. 5.-Total urinary urea (mg.) versus average blood urea (mg. $100 \mathrm{ml}$.) during the first day of life. Symbols as in Fig. 1.

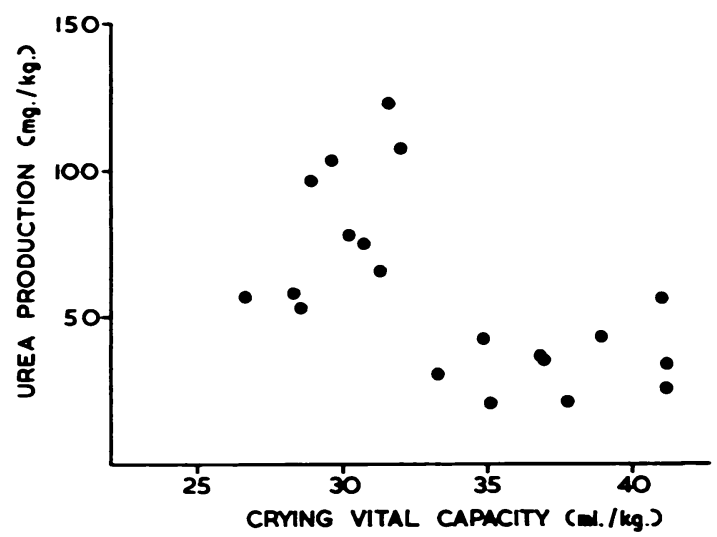

FK. 6.-Urea production (mg/kg.) versus average crying vital capacity (ml. kg.) during the first day of life. Correlation $\mathrm{r}=-0.576, \mathrm{p}, 0.01$.

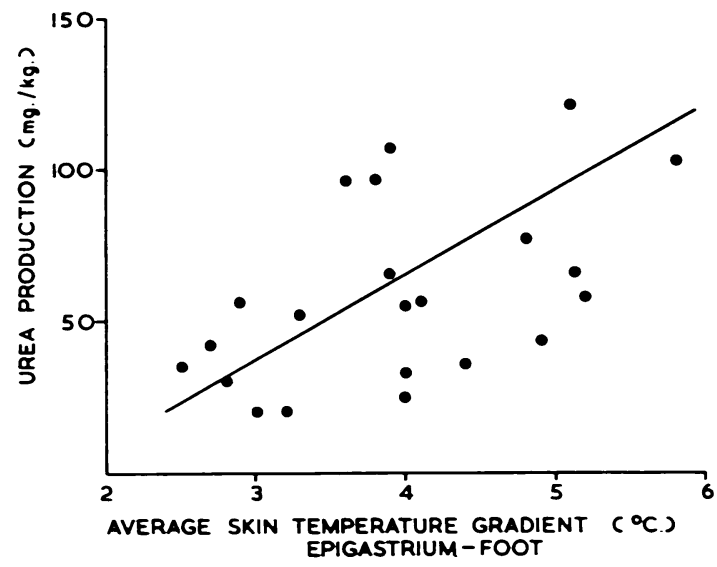

Fig. 7.-A verage skin temperature gradient, epigastrium minus foot, versus urea production (mg. $\mathrm{kg}$.) during the first day of life. Correlation $\mathrm{r}=+0.596, \mathrm{p}<0.01$. linear, and one might conclude that the efficiency of mechanical pulmonary ventilation is only a reflection of some other factor(s) affecting the quantitative production of this protein breakdown product.

A further possibility is that respiratory function, as measured by the crying vital capacity, and urea production, are both related to the distribution of circulation during the first day of life, and the latter thus is a resultant of metabolic activity in well and poorly perfused tissue. Direct measurement of peripheral blood flow was not carried out, but an approximation of limb skin blood flow ('peripheral') as compared with skin blood flow over the epigastrium ('central') could be obtained from the difference between skin temperature over the epigastrium and on the sole of the foot, measured five to six times during the first day under standard conditions.

Fig. 7 shows average differences between 'central' and 'peripheral' skin temperatures plotted against urea production. The correlation coefficient is positive: the relatively cooler the feet, the higher the calculated urea production.

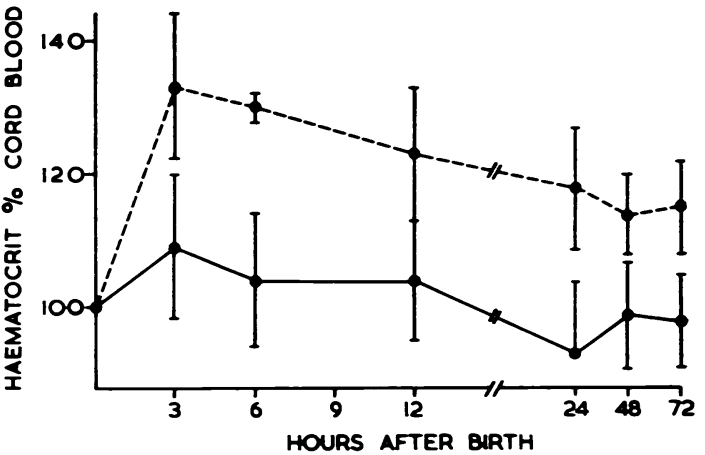

FIG. 8. - Changes in haematocrit during the first three days of life in infants allowed to receive a maximal (upper curve-15 infants) or a minimal (lower curve-14 infants) placental transfusion. Ordinatehaematocrit in percentage of cord blood values.

Fluid Shifts Occurring During First Day. Fig. 8 shows haematocrit values of cord and heel-prick blood in infants with early and late clamping of the umbilical cord. The values are generally in agreement with those reported in the literature, and infants allowed to receive a maximal amount of blood from the placenta maintained significantly higher haematocrits during the first three days of life.

Infants with a large placental transfusion as a group also had systolic blood pressure readings some 5-6 $\mathrm{mm}$. $\mathrm{Hg}$ higher than those with small $(70.6 \mathrm{~mm}$. as compared with $64 \cdot 1$ ), although variation within groups rendered this difference insignificant. Correlation with body weights or haematocrit level was not consistent, and by 72 hours after birth differences 


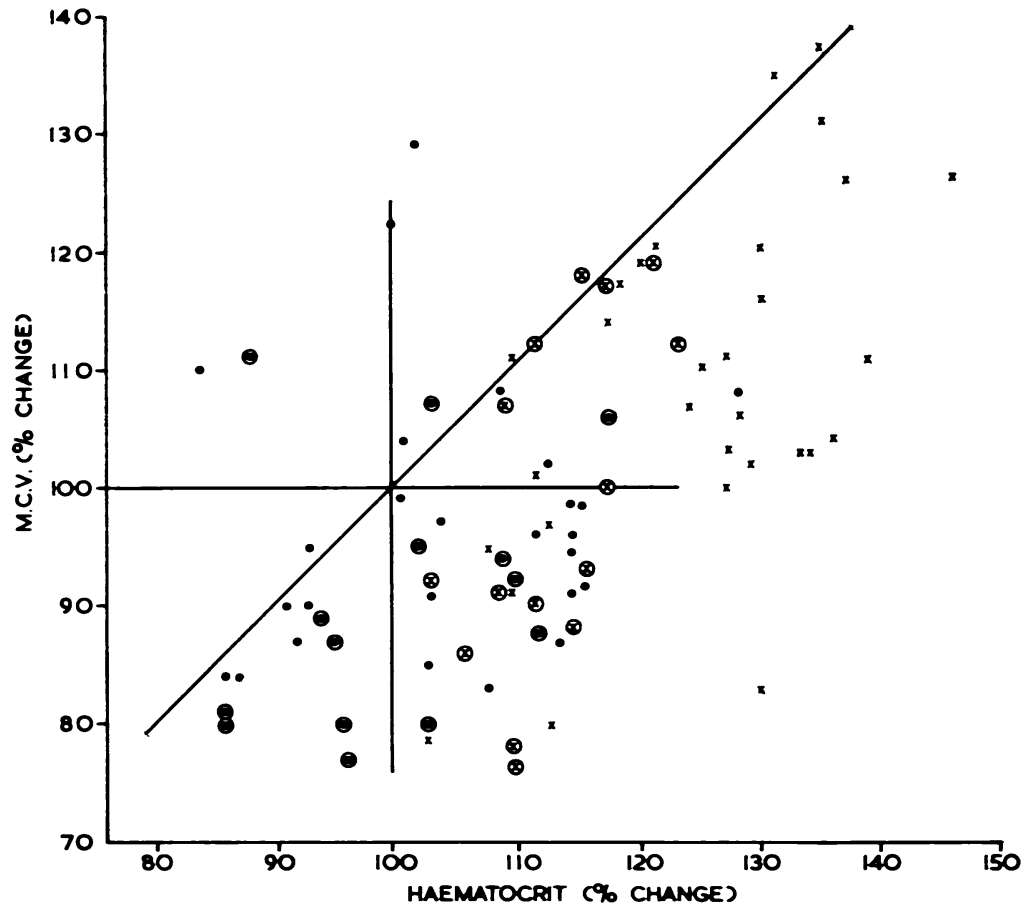

FKG. 9. - Changes in hacmatocrit versus changes in mean corpuscular volume the first three days of life. Circled points are those at 48 and 72 hours.

If changes were strictly parallel, points would fall on the line bisecting the axes.

between the groups had disappeared $(74 \cdot 4$ and $74 \cdot 3$ mm. average).

The marked rise in haematocrit occurring during the first three to six hours after birth has been interpreted (Gairdner, Marks, Roscoe and Brettell, 1958) as indicating a shift of plasma out of the circulating blood and, in fact, most direct measurements of plasma and blood volume (Steele, 1962; Usher, Shephard and Lind, 1963) have confirmed this deduction. Fig. 9 shows that the red blood cells participate to some, though a variable, extent in a fluid shift. The percentage change in haematocrit, however, almost always exceeds that in mean corpuscular volume by up to $20 \%$.

Another method of demonstrating a shift in the distribution of fluid is by direct measurement, as described by Sutherland and co-workers (1959). In 10 infants changes in leg volume were measured by water displacement $1,2,3,6,12,18$, and 24 hours after birth. This method, though simple in principle, proved to require stringent precautions and the taking of four to five readings to ensure an acceptable degree of accuracy.

Five illustrative courses of changes in leg volume are shown in Fig. 10. It was surprising to find such differences both in the amount of fluid accumulation, and, to a lesser extent, the time course of volume changes. Neither bore any constant relation to the size of presumed placental transfusion, and it was not possible in such a small series to deduce with any certainty factors influencing the rate of fluid accumulation.

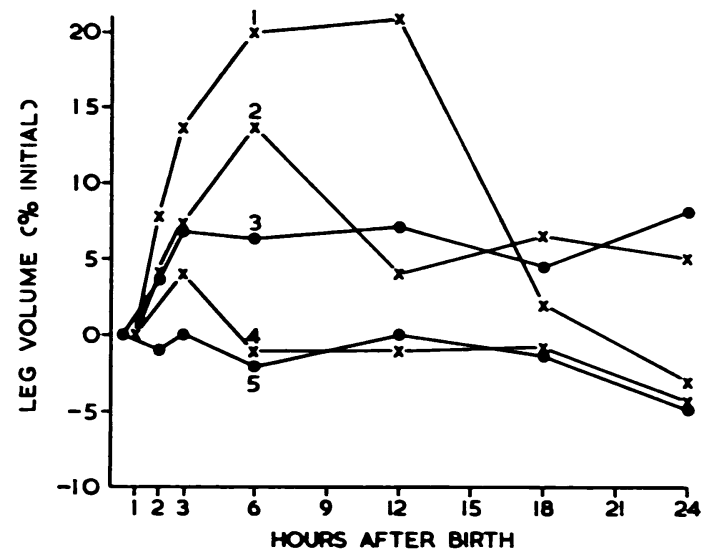

FiG. 10. - Five illustrative courses of changes in leg volume during the first day of life. 1.- small baby, large transfusion, true knot in cord: 2. - large baby, large transfusion; 3. - large baby, small transfusion; 4.- small baby, large transfusion; 5. - small baby, small transfusion. 
'Recognition' of Blood Volume by Newborn Infants. It seems apparent from Fig. 4 that newborn infants did not regulate $\mathrm{Na}$ excretion according to whether they received a large or small amount of blood from the placenta. The maximum increment of blood volume in the infant following delayed clamping of the umbilical cord has been generally taken as about $20^{\circ}$, although a recent report by Usher and coworkers (1963) has placed this as high as $60^{\circ}{ }_{0}$ of total blood volume.

The rather surprising lack of correlation between renal $\mathrm{Na}$ output in the first day of life and a theoretical difference in blood volume of such magnitude between infants with 'maximal' and 'minimal' placental transfusions gives rise to a number of speculations. Either newborn infants lack the adult's renal response to changes in blood volume (Cort, 1963), or they react to different stimuli in a different manner, or they manage to compensate for blood volume differences due to placental transfusion.

Although total estimated 'milliosmolar' output was dependent upon total urine flow (Fig. 3), Na excretion as such was not, at least, in many cases. Fig. 4 shows that in a number of infants, relatively high urine flows were associated with low $\mathrm{Na}$ excretion, indicating active retention of $\mathrm{Na}$ in such infants.

No correlation whatever was apparent between the size of the crying vital capacity and $\mathrm{Na}$ output, but in the absence of evidence relating crying vital capacity to the amount or pressure of blood in the pulmonary circuit in normal infants, no conclusions can be drawn as to its physiological meaning.

No correlation was found between the absolute haematocrit level or its degree of change, blood pressure, or between levels or changes in skin temperature and $\mathrm{Na}$ excretion.

Two clear correlations were found, however: the first was between $\mathrm{Na}$ output and the cumulative change in leg volume (Fig. 11), and the possible haemodynamic significance of this will be discussed;

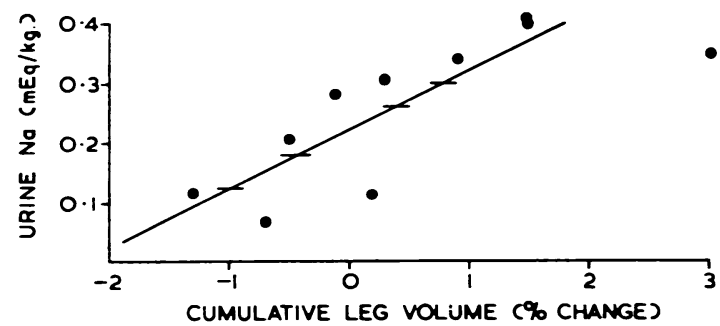

FKG. 11.-Cumulative leg volume changes versus urinary $\mathrm{Na}$ output ( $\mathrm{mEq}$ kg.) in 10 newborn infants in the first day of life. Correlation $\mathbf{r}=-0.718 . \mathbf{p}>0.01<0.02$.

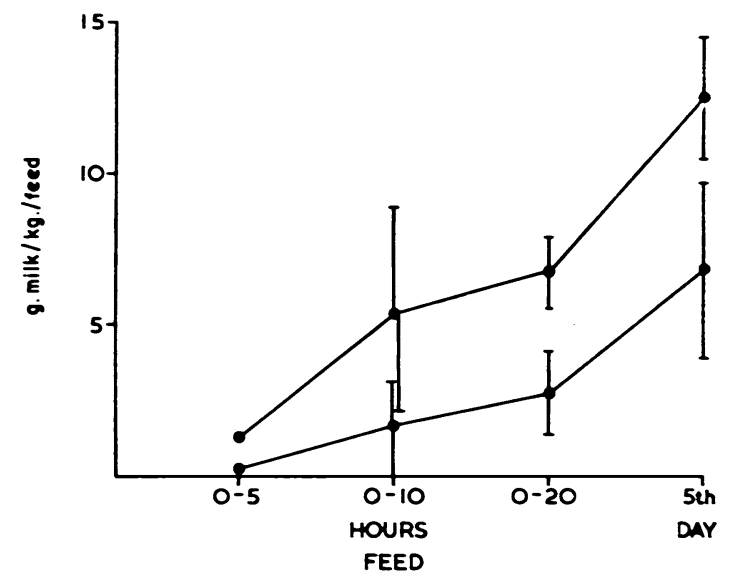

FiG. 12.-Milk taken from the breast (g. kg. feed) by 12 infants with a minimal placental transfusion (upper curve) and 13 infants with maximal (lower curve). Amounts are shown for feeds 0-5. 0-10. 0-20 and fifth day. Six feeds daily.

Differences for feeds $0-20$ and fifth day: $t=7 \cdot 18, t=5 \cdot 34$ respectively, p $<0.01$.

the other was a striking response to the size of placental transfusion in regard to milk intake from the breast (Fig. 12), with babies receiving small transfusions drinking much more milk. both absolutely and per $\mathrm{kg}$. birth weight, than babies allowed a large transfusion.

\section{Discussion}

This study was a complex one, including a number of physiological systems simultaneously, and as such demanded certain compromises in approach. Since we could expect considerable variation even within a group of clinically normal newborn infants, the decision was taken to gather as much information from individual babies as possible, at as frequent intervals as possible. It was thus thought to be of advantage to use many atraumatic, if simple, methods of investigation rather than few more technically involved and traumatic ones at relatively infrequent intervals.

A wide range of values on the amount of blood remaining in the placenta was found, even when the time of cord clamping was standard, although lateclamped infants clearly received more blood than early-clamped infants. It has not been our experience that the position of the infant relative to the placenta plays a decisive role in governing 'siphoning' of blood in or out of the placenta (Lancet, 1962), and, indeed, one would not expect it to from the hydrostatic pressures involved. Our mothers received no anaethesia or atropine-type premedication during labour, which might conceivably affect cardiovascular or ductus venosus sphincter activity in infants. 
A fairly wide variation in the amount of urine passed on the first day of life was found, and we are inclined to share the impression of Fisher, Pyle, Porter, Beard, and Panos (1963) that quantitatively urine flow in the early neonatal period reflects intrinsic stores of 'excess fluid'. Individual variations in these stores, if such they are, seemed to outweigh in many babies the changes in total body fluids which could be achieved by allowing a maximal or minimal placental transfusion.

There was no clear relation of urinary volume or concentration to the concentration of maternal urine at the end of the second stage of labour, although 2 infants (not included here), whose mothers were given $300-500 \mathrm{ml} .5^{\circ}$ o glucose during the second stage, passed large amounts of urine during the first day, about $20 \mathrm{ml}$. $/ \mathrm{kg}$. (R. L. Cort and H. Přibylová, 1963, unpublished observations).

In the case of urea excretion, the amount of urea 'produced' seemed to be the largest single factor. This in turn was related both to crying vital capacity and the gradient in skin temperatures between the foot and epigastrium. The suggestion has been made that these correlates to urea production reflect distribution of blood flow. If, as Burnard reported (1958), the presence of an open ductus arteriosus shunt in the newborn infant is related to respiratory function, one would predict that infants with poor respiratory function (chiefly pulmonary ventilation?) would have ductus shunts of greater size and/or duration than those with satisfactory establishment of pulmonary function, and thus lower aortic and peripheral blood flows. In fact, Celander and Mårild (1962) have mentioned low levels of peripheral blood flow in asphyxiated infants. Further evidence concerns measurement of skin blood flow in newborn infants (R. L. Cort and H. Přibylová, 1963, unpublished observations). In several very young infants, crying, which probably reverses the usual left-to-right shunt, was promptly followed by very large increases in skin blood flow.

Our findings supplement those of McCance and Widdowson (1954) on increased 'tissue destruction' following traumatic birth and extend them to include babies born under clinically normal conditions.

A relatively larger $\mathrm{Na}$ output (though still much smaller than in premature infants) was associated with at least three circumstances: abnormality of the umbilical cord circulation, possible intrapartum anoxia or infection, and large birth weight. There was also some suggestion that 'maximal' or 'minimal' placental transfusion influenced $\mathrm{Na}$ output, particularly in large babies (see Table 2).

A possible common denominator for factors associated with $\mathrm{Na}$ excretion should take into account the following.

(a) A large or small placental transfusion is not in itself a decisive factor in determining urinary $\mathrm{Na}$ output in the first day of life. The latter is probably partially related to the rate of urine flow, as is the total output of urinary constituents.

(b) Disturbances in cord circulation in 4 infants were associated with relatively large $\mathrm{Na}$ excretion: 3 of the 4 fell on to the curve relating increment in leg volume to $\mathrm{Na}$ output.

(c) Large infants, weighing $3,700 \mathrm{~g}$. or more at birth, tended to excrete more $\mathrm{Na} / \mathrm{kg}$. than smaller infants, with 2 exceptions out of 10 . Is this because they have in general larger blood or extracellular fluid volumes relative to weight, or do 'volume regulatory' reflexes play a role? Reference to the published reports (Steele, 1962; Low, Kerr and Cochon, 1963; Usher et al., 1963) reveals either no constant relation of body weight to measured blood volume, or maximal differences of $4-6 \mathrm{ml} . / \mathrm{kg}$. between large and small babies. It is possible that calculation of blood volume per $\mathrm{kg}$. of total body weight rather than of lean body mass introduces an error in plump infants.

A significant relation was found between the cumulative gain or loss of leg volume (presumably extracellular fluid) and the rate of $\mathrm{Na}$ excretion. The conditions governing capillary filtration in the newborn are not simple (Celander and Mårild, 1962) and not directly related to the rate of peripheral blood flow. The most likely explanation for the correlation found is that central venous pressure underlies both fluid transfer in the leg and facultative $\mathrm{Na}$ excretion. This would be consistent with two other pieces of evidence. One is the high rate of fluid and $\mathrm{Na}$ excretion of premature infants surviving the respiratory distress syndrome, but not evident in fatal cases (Cort, 1962): Bonham Carter, Bound, and Smellie (1956) reported that such surviving infants had increased central venous pressures, while infants who failed to survive respiratory distress tended to have normal levels. The other is the finding of Taylor et al. (1961) (see also Jegier, Blankenship, and Lind, 1963) of a time course of falling central venous pressure in the first hours of life, which seems at least compatible with the time course of leg volume changes in our data. In order to demonstrate that central venous pressure might be an afferent signal for $\mathrm{Na}$ excretion in the newborn infant an integral expression of central venous pressure relative to urinary $\mathrm{Na}$ is necessary, rather than measurements isolated in time and few in number.

The difference in spontaneous breast milk intake in relation to the size of placental transfusion was 
striking, and quite without exception infants receiving a 'minimal' transfusion took significantly more from the breast than those receiving a 'maximal'. As far as possible in this small series, conditions that might possibly influence establishment of lactation were standard. Only infants of primiparous mothers were considered, and average birth weight as well as maternal age were similar. Babies were first put to the breast after 24 hours, when virtually all mothers are beginning to secrete milk, and thus variations in infants' nursing vigour would tend not to be obscured by variations in the onset of maternal lactation. This finding has theoretical importance in suggesting the presence of an inborn, unconditioned 'volume regulatory' reflex utilizing the rather limited capabilities of the newborn infant to repair deficits in body fluid volume. Whether this reflects 'hunger' or 'thirst' is an academic question, for under physiological conditions the infant's milk intake satisfies both.

Practically, it is useful in stressing the infant side of the lactation partnership and pointing up the necessity of studying and respecting variations in infants' nursing activity in promoting lactation (Archavskii, 1952).

\section{Summary}

The effect of 'maximal' or 'minimal' placental transfusions upon urinary excretion of $\mathrm{Na}, \mathrm{K}, \mathrm{Cl}$ and urea, as well as haematocrit, skin temperatures, systolic blood pressure, changes in leg volume, and crying vital capacity, has been studied in normal newborn infants.

Urinary volume and concentration were in no clear relation to the time interval after birth or to the size of placental transfusion. Total estimated milliosmolar excretion, above urine volumes of $15-20 \mathrm{ml}$. in the first day of life, was dependent upon the total amount of urine passed. The amount of urea 'produced' was inversely related to the size of the crying vital capacity and directly related to the gradient in skin temperatures between the foot and epigastrium on the first day of life. The suggestion is made that these relations reflect blood flow distribution and tissue perfusion.

The excretion per $\mathrm{kg}$. birth weight tended to be larger following disturbances in cord circulation, possibly after intrapartum anoxia or infection and in most large babies (of birth weight $3,700 \mathrm{~g}$. or more).

Though $\mathrm{Na}$ excretion was not clearly related to the size of presumed placental transfusion, it was directly related to the cumulative change in leg volume (extracellular fluid?) on the first day of life.

Newborn infants receiving a 'minimal' placental transfusion took significantly more milk from the breast than those receiving a 'maximal' amount of blood from the placenta.

We thank our research sisters $H$. Vydláková, $H$. Kupková, S. Nováková, and V. Janoušková for assistance in gathering data, and the technicians of the paediatric research laboratory for their help with biochemical determinations.

\section{REFERENCES}

Archavskii, I. A. (1952). Immediate breastfeeding of newborn infants in the prophylaxis of the so-called physiological loss of weight. [In Russian]. Vop. Pediat., 20. No. 5, p. 45.

Ashworth, A. M., Neligan, G. A. and Rogers. J. E. (1959). Sphygmomanometer for the newborn. Lancet, 1, 801.

Bonham Carter, R. E.. Bound. J. P. and Smellie, J. M. (1956). Mean venous pressures in the first hours of life. ibid., 2, 1320.

Burnard, E. D. (1958). A murmur from the ductus arteriosus in the newborn baby. Brit. med. J.. 1. 806.

Celander, O. and Mảrild. K. (1962). Regional circulation and capillary filtration in relation to capillary exchange in the foot and calf of the newborn infant. Acta paediat. (Uppsala), 51, 385.

Cort, J. H. (1963). Relation of the central nervous system to water and electrolyte metabolism: Physiologic and clinical aspects. In Clinical Metabolism of Body. Water and Electrolytes, ed. J. H. Bland, p. 486. Saunders, Philadelphia.

Cort. R. L. (1961). Fractional collection of urine in very small or ill infants. Acta paediat. (Uppsala). 50, 385.

- (1962). Renal function in the respiratory distress syndrome. ibid., 51. 313 .

- Pribylová, H. and Znamenácek. K. (1962). Placental transfusion. Lancet, 2. 151.

Fisher, D. A., Pyle, H. R.. Jr.. Porter. J. C., Beard, A. G. and Panos, T. C. (1963). Control of water balance in the newborn. Amer. J. Dis. Child., 106, 137.

Gairdner, D., Marks. J., Roscoe. J. D. and Brettell, R. O. (1958). The fluid shift from the vascular compartment immediately after birth. Arch. Dis. Childh., 33, 489.

Jegier, W., Blankenship. W. and Lind. J. (1963). Venous pressure in the first hour of life and its relationship to placental transfusion. Acta paediat. (Uppsala), 52, 485.

Lancet (1962). Leading article. Placental transfusion. 1. 122.

Low, J. A., Kerr, N. D. and Cochon. A. R. (1963). Plasma and blood volume of the normal newborn infant and patterns of adjustment in initial 24 hours of the neonatal period. Amer. J. Obstet. Gynec.. 86, 886.

McCance, R. A. and Widdowson, E. M. (1954). The influence of events during the last few days in utero on tissue destruction and renal function in the first two days of independent life. Arch. Dis. Childh., 29, 495.

Steele. M. W. (1962). Plasma volume changes in the neonate. Amer J. Dis. Child., 103.10.

Sutherland, J. M., Oppe. T. E., Lucey. J. P. and Smith, C. A. (1959). Leg volume changes observed in hyaline membrane disease. ibid., 98, 24.

_ and Ratcliff, J. W. (1961). Crying vital capacity. ibid., 101, 67.

Taylor, P. M., Egan, T. J., Birchard, E. L.. Bright, N. H. and Wolfson, J. H. (1961). Venous hypertension in the newborn infant assocjated with delayed clamping of the umbilical cord. Acta paediat. (Uppsala), 50, 149.

Usher, R., Shephard, M. and Lind, J. (1963). The blood volume of the newborn infant and placental transfusion. ibid., 52, 497. 